\title{
PROGRESS REPORT OF FY 1999 ACTIVITIES: CONTINUED DEVELOPMENT OF AN INTEGRATED SOUNDING SYSTEM IN SUPPORT OF THE DOE/ARM EXPERIMENTAL PROGRAM
}

Principal Investigators:

$\begin{array}{lr}\text { Edgeworth R. Westwater CIRES/NOAA } \\ \text { Yong Han } & \text { CIRES/NOAA } \\ \text { Vladimir Leuskiy } & \text { CIRES/NOAA }\end{array}$

\begin{abstract}
Both during September 15-30 1996 and September 15 - October 5, 1997, the Environmental Technology Laboratory (ETL) participated in experiments at the Southern Great Plains (SGP) Cloud and Radiation Testbed (CART) site that was designed to study many of the ways that $A R M$ is measuring water vapor. Because of some inconsistencies between ETL and ARM Microwave radiometers (MWR) during these experiments, called the Water Vapor Intensive Operating Periods (WVIOPs), we applied to both sets of data a newly developed correction algorithm for tipping curve calibration. We found that this algorithm reduces the differences between the radiometers, there are still some unexplained features of scanning ARM MWR data.
\end{abstract}

Measurements of water vapor at the North Slope of Alaska and Adjacent Arctic Ocean (NSA/AAO) CART site in Barrow, Alaska, are a potential problem because of the difficulty of radiosondes to measure low amounts of vapor during cold and extremely dry conditions. The applicability of MWR scaling to radiosondes is questionable because of the low sensitivity of these instrument during dry conditions. It has been suggested by the ARM Instaneous Radiative Flux Working Group and others that measurements of brightness temperature around $183 \mathrm{GHz}$ could be used to scale radiosondes during the coldest and driest periods. However, the millimeter wavelengths are vulnerable to cloud effects from both liquid and ice. During March 1999, we participated in the joint NASA/NOAA Millimeter wave Arctic Experiment to evaluate microwave and millimeter wave radiometers during extremely cold conditions.

ETL tested, both in an experiment at the Boulder Atmospheric Observatory and during the two Water Vapor Intensive Operating Periods in 1996 and 1997, a 5-mm scanning radiometer that measures low-altitude temperature profiles; both profiles of lapse rate and absolute temperature can be measured with the instrument. Results of these tests were published in the open literature. In addition, the ETL scanning radiometer was operated at the NSA/AAO in March 1999.

\section{APPLICATION OF TIPPING CALIBRATION METHOD TO ARM MWR DATA}

Results of the 1997 WVIOP (Westwater et al., 1998A; Westwater et al., 1998 B) indicated that the ARM MWR produced measurements of PWV that were about two millimeters higher than measurements from a variety of other independent instruments, such as two ETL 


\section{DISCLAIMER}

This report was prepared as an account of work sponsored by an agency of the United States Government. Neither the United States Government nor any agency thereof, nor any of their employees, make any warranty, express or implied, or assumes any legal liability or responsibility for the accuracy, completeness, or usefulness of any information, apparatus, product, or process disciosed, or represents that its use would not infringe privately owned rights. Reference herein to any specific commercial product, process, or service by trade name, trademark, manufacturer, or otherwise does not necessarily constitute or imply its endorsement, recommendation, or favoring by the United States Government or any agency thereof. The views and opinions of authors expressed herein do not necessarily state or reflect those of the United States Government or any agency thereof. 


\section{DISCLAIMER}

Portions of this document may be illegible in electronic image products. Images are produced from the best available original document. 
MWR's, two Global Positioning Systems, and ARM Balloon Borne Sounding Systems (BBSS). These results were in contrast to results obtained during WVIOP'96, in which ETL and ARM MWR's were basically in agreement. Based on a newly developed correction algorithm to the tipping calibration method (Han and Westwater, 1999), we applied a variety of corrections to the ARM MWR data, and found that, in particular, the beamwidth correction accounted for a significant part of the bias. What was more surprising, we found that the ARM MWR tipping calibrations were inconsistent with each other; i.e., the data at 2, 2.5, and 3.0 airmasses, when normalized to zenith, were not in agreement. If the data at 1 and 2 airmasses were used, ARM and ETL radiometers agreed; if data at 2.5 and 3 airmasses were used, the radiometers did not agree. However, since the 1998 progress report, the BBSS data have been revised by Lesht (1999) and now agree better with corrected ARM MWR data.

\section{References}

E. R. Westwater, Y. Han, S. I. Gutman, and D. E. Wolfe: (1998 A): "Remote sensing of total precipitable water vapor by microwave radiometers and GPS during the 1997 Water Vapor Intensive Operating Period," Proc. IGARSS'98, 6-19 July, 1998, Seattle, WA 2158-2162.

E. R. Westwater, Y. Han, S. I. Gutman, and D. E. Wolfe: (1998 B): "Remote sensing of column integrated water vapor by microwave radiometers and GPS during the 1997 Water Vapor Intensive Operating Period," Proc. Eighth ARM Science Team Meeting, March 23-27th, 1998, Tucson, Arizona, 799-803.

\section{PARTICIPATION IN NSA/AAO WATER VAPOR EXPERIMENT}

There are concerns about the ability of the ARM Microwave radiometer (MWR) to derive accurate measurements of Precipitable Water Vapor (PWV) during the coldest and driest of conditions, because of the relatively weak response of the $22 \mathrm{GHz}$ emission to PWV amounts below about $5 \mathrm{~mm}$. A theoretical analysis (Jones and Racette, 1998) indicated that measurements of atmospheric emission in the $\mathrm{mm}$ wavelength region can provide increased accuracy of PWV determination during these cold conditions. During March 1999, scientists from NASA/Goddard Space Flight Center and from NOAA/ETL participated in the Millimeterwave Radiometric (MMWR)-Arctic experiments to determine if radiometric measurements around the much stronger $183 \mathrm{GHz}$ absorption line can yield improved measurements of PWV during the extreme cold conditions. Instruments deployed are shown in Table 1. 


\begin{tabular}{|c|c|c|}
\hline Instrument & Organization & Frequencies (GHz) \\
\hline $\begin{array}{l}\text { Millimeter-wave imaging } \\
\text { Radiometer (MIR) }\end{array}$ & NASA/GSFC & $\begin{array}{c}89,150,183.31 \pm(1, \pm 3, \pm 7) \\
220,340\end{array}$ \\
\hline $\begin{array}{l}\text { DOE Multichannel Microwave } \\
\text { Radiometer (DoER) }\end{array}$ & NASA/GSFC & $\begin{array}{c}20.735,21.485,22.235,22.985 \\
23,735,36.5, \text { and } 89\end{array}$ \\
\hline $\begin{array}{c}\text { Circularly Scanning Radiometer } \\
\text { (CSR) }\end{array}$ & NOAA/ETL & $\begin{array}{c}20.6,31.65,183.31 \pm(0.5, \pm 1, \pm \\
3, \pm 5, \pm 7, \pm 12, \pm 15), 325 \pm(1, \pm \\
3, \pm 8), 340 \mathrm{H} \& \mathrm{~V}, 10 \mu \mathrm{m}\end{array}$ \\
\hline Scanning $\mathrm{O}_{2}$ Radiometer & NOAA/ETL & 60.5 \\
\hline $\begin{array}{l}\text { Vaisala and chilled mirror } \\
\text { surface met. }\end{array}$ & NOAA/ETL, NCAR & \\
\hline $\begin{array}{l}\text { Vaisala and chilled mirror } \\
\text { radiosondes }\end{array}$ & ARM & \\
\hline
\end{tabular}

\section{Millimeter wavelength observations of water vapor at the NSA/AAO}

Presently, ARM operates at their NSA/AAO CART site a MWR which measures downwelling radiation at 23.8 and $31.4 \mathrm{GHz}$ from which PWV and LWP are retrieved. Data from this instrument represent the baseline from which millimeter-wave observations will be compared. For PWV amounts greater than $1 \mathrm{~cm}$, this pair of frequencies is able to obtain accurate measurement. When the atmosphere becomes very dry the absorption around the $22.235 \mathrm{GHz}$ water vapor line becomes weak. Thus, the relative uncertainty in retrieved PWV increases with decreasing water vapor. The $183 \mathrm{GHz}$ absorption line is about 100 times stronger than that of the 22.231 GHz line. Improved estimates of low PWV can be obtained by taking advantage of the much stronger $183 \mathrm{GHz}$ water vapor line. A preliminary look at our data demonstrates the greater sensitivity of the mm-wave frequencies. Responses of seven of the radiometer channels from March 11 are plotted in Figure 1. The PWV for this day is less than $2 \mathrm{~mm}$ and the temperatures were colder than $-37^{\circ} \mathrm{C}$. The brightness temperature values at 5:00 UTC have been subtracted and the temperature differences for the remainder of the day are shown. The response of the channels at $23.8 \mathrm{GHz}$ and $31.4 \mathrm{GHz}$ vary by no more than $\sim 1$ degree. The mm-wave channels on the other hand exhibit variations of 10 to 20 degrees. Further analysis of this data will yield estimates of the errors associated with retrieving PWV using various combinations microwave and mm-wave frequencies. These observations confirm the greatly enhanced sensitivity of the millimeter wave observations, relative to the ARM MWR, at low temperatures and dry atmospheres. 

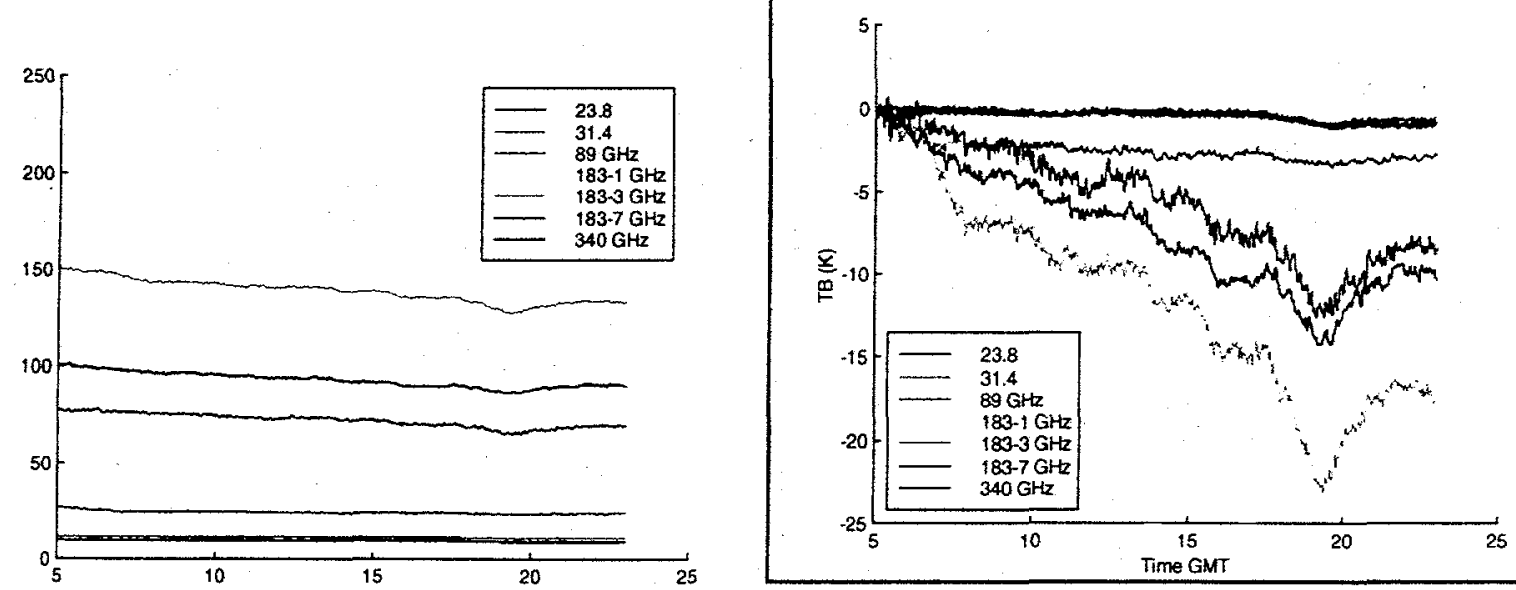

Figure 1: The response of seven of the channels are plotted as differences in brightness temperature referenced to 5:00 UTC on March 11. The microwave channels exhibit a small response whereas the mm-wave channels detect the changes in the atmosphere on this clear dry day.

\section{References}

Jones, D. C., and P. E. Racette, 1998: Ground-based retrieval of very low to high columnar integrated water vapor using combined millimeter- and microwave observations. Proc. International Geophysics And Remote Sensing Symposium '98, 6-10 July, 1998, Seattle, Washington (in press)

P. E. Racette, E. R. Westwater, Y. Han, Al Gasiewski, Ed Kim, M. Klein, K. Widener, B. Zak (1999): Millimeter Wave Radiometric Arctic Winter Experiment. Proc. $9^{\text {th }}$ ARM Science Team Meeting, San Antonio, Texas, March 22-26, 1999 (in press).

\section{TESTING OF 5-MM SCANNING RADIOMETERS AT NSA/AAO}

An open literature paper was published describing the results of an experiment conducted from November 1996 to January 1997 at the Boulder Atmospheric Observatory (BAO) (Westwater et al., 1999). In this experiment, data from two scanning 5-mm radiometers and a Radio Acoustic Sounding System were compared against in situ tower data. In addition, we operated the ETL 5-mm scanning radiometer during the March 1999 experiment at the NSA/AAO. Data from the ATTEX 5-mm radiometer, purchased by ARM from a Russian firm, the ETL instrument, tower, and radiosondes, were taken and will be compared to determine the accuracy of the systems.

References

E. R. Westwater, Y. Han, V. G. Irisov, V. Leuskiy, E. N. Kadygrov, and S. A. Viazankin (1999): 
Remote Sensing of Boundary-Layer Temperature Profiles by a Scanning 5-mm Microwave Radiometer and RASS: Comparison Experiment., J. Atmospheric Oceanic Technology, 16(7), 805-818.

\section{FY 2000 PLANS}

\section{Southern Great Plains CART}

A high quality calibration reference source for MWRs operating has been purchased and will shortly be delivered to ETL. We will take the calibration reference source to the SGP Central Facility and conduct calibration experiments with the ARM MWR.

We will change our focus from measurements of water vapor to those of clouds. The WVR has already been shown to measure liquid water path and, with the addition of ceilometer data, to yield a first-order profile of liquid water density (Han and Westwater, 1995). Although WVR data is widely used for the determination of liquid water path, only a very limited amount of in situ ground truth data has been used for verification. We propose to participate in cloud IOPs where in situ and other sources of cloud data will be available. The newest source of data will be that the CART cloud radar, which will add important information on cloud thickness. In addition, we plan to evaluate a technique using both GPS and MWR data to derive cloud liquid.

\section{North Slope of Alaska}

We will complete the analysis of the radiometer data taken during the March 1999 NSA/AAO Millimeter wave Arctic Experiment and make recommendations to ARM about $183 \mathrm{GHz}$ deployment. An open literature article will also be submitted.

We will complete the analysis of the 5-mm scanning radiometer data taken during the March 1999 NSA/AAO and make recommendations to ARM about further operation with the ATTEX instrument.

We will also investigate the microwave radiative properties of arctic clouds, based on the wide variety of multi-frequency observations that were taken in March 1999.

Based partially on the results of the 1999 experiment, we will also recommend to ARM further experiments to study arctic clouds, temperature, and water vapor.

PAPERS PUBLISHED SINCE OCTOBER 1, 1997

Open Literature Refereed Papers:

Y. Han , E. R. Westwater, and R. A. Ferrare (1997): Applications of Kalman Filtering to Derive Water Vapor from Raman Lidar and Microwave Radiometers. J. Atmos. Oceanic Technol. , vol. 14, No. 3, Part 1, June, 1997. pp. 481-487. 
Y. G. Trokhimovski, E. R. Westwater, Y. Han, and V. Ye. Leuskiy (1998):"The results of Air and sea surface temperature measurements using a $60 \mathrm{GHz}$ microwave rotating radiometer," IEEE TGARS, Vol. 36, No. 1, 3-15.

Y. Han, and E. R. Westwater (1999): Analysis and improvement of tipping calibration for ground-based microwave radiometers. IEEE Trans. Geosci. And Remote Sensing (in press).

Y. Han, and E. R. Westwater, (1999): Analysis of Tip Cal Methods for Ground-based Microwave Radiometric Sensing of Water Vapor and Clouds. Microwave Radiometry and Remote Sensing Applications. VSP Press (in press).

F. Solheim, J. R. Goodman, R. H. Ware, E. R. Westwater, and Y. Han: (1998) Radiometric temperature, water vapor, and cloud liquid water profiling with various inversion methods, Radio Sci., 33, 393-404.

E. R. Westwater, (1997): Remote sensing of tropospheric temperature and moisture by integrated observing systems. Bull. Amer. Meteor. Soc.,78, 1991-2006

E. R. Westwater, Y. Han, V. G. Irisov, V. Ye. Leuskiy, Yu. G. Trokhimovski, C. W. Fairall, and A. Jessup (1998): Sea-Air and Boundary Layer Temperatures Measured by a Scanning 5-mm wavelength (60 GHz) Radiometer: Recent Results. Radio Sci., 33, 291-302.

E. R. Westwater, Y. Han, J. B. Snider, K. S. Gage, W. Ecklund, A. Riddle, J.H. Churnside, J. A. Shaw, M. J. Falls, C. N. Long, and T. P. Ackerman (1999): Ground-Based Remote Sensor Observations during PROBE in the Tropical Western Pacific. Bull. Amer. Meteor. Soc., 80(2), $257-270$.

E. R. Westwater, A. S. Viazankin Y., K. Gaikovich, E. N. Kadygrov (1999): Radiometric monitoring of the temperature of the planetary boundary layer of the atmosphere. Russian Meteorology and Hydrology, N2, February 1999 (in Russian)

Ed R. Westwater,Yong Han, and Fred Solheim (1999): Resolution and accuracy of a multifrequency scanning radiometer for temperature profiling. Microwave Radiometry and Remote Sensing Applications. VSP Press (in press).

E. R. Westwater, Y. Han, V. G. Irisov, V. Leuskiy, E. N. Kadygrov, and S. A. Viazankin (1999): Remote Sensing of Boundary-Layer Temperature Profiles by a Scanning 5-mm Microwave Radiometer and RASS: Comparison Experiment., J. Atmospheric Oceanic Technology, 16(7), 805-818.

Conference Proceedings

D. Turner, T. Shippert, J. Liljegren, Y. Han, and E. Westwater (1997) Initial analysis of water vapor and temperature profiles retrieved from integrated ground-based remote sensors. Proc. 6th ARM Science Team Meeting. San Antonio, TX, March 4-7, 1996 327-330. 
C. W. Fairall, P. Hacker, E. F. Bradley, S. Anderson, Y. du Penhoat, C. Eriksen, K. S. Gage, S. Kennan, M. LeMone, M. McPhaden, C. Ohlmann, D. Parsons, C. Paulson, R. Pinkel, S.

Rutledge, A. Soloviev, R. Weller, E. Westwater, and E Zipser (1999): "The Legacy of COARE for Technology and Ocean-Atmosphere Observing Capability", Proceedings of a conference on the TOGA COUPLED OCEAN-ATMOSPHERE RESPONSE EXPERIMENT (COARE), Boulder, Colorado, 7-14 July 1998. WCRP-107,WMO/TD-NO. 940, 116-138.

Y. Han, E. R. Westwater, and R. A. Ferrare (1997): "Recent Results in Deriving Water Vapor Profiles from Combined Remote Sensor Observations using Kalman Filtering" Proceedings of Sixth ARM Science Team Meeting, San Antonio, Texas, March 4-7, 1996 . 121124.

Y. Han, Ed R. Westwater, J. Shaw, and J. H. Churnside, (1998): "Comparison of boundarylayer temperature retrievals from a FTIR and a 5-mm microwave radiometer during the 1997 Water Vapor Intensive Operating Period," Proc. Eighth ARM Science Team Meeting, March 23-27th, 1998, Tucson, Arizona, 313-316.

Y. Han, Ed R. Westwater, J. Shaw, and J. H. Churnside, (1998): "Comparison of boundary-layer temperature retrievals from a FTIR and a 5-mm microwave radiometer during the 1997 Water Vapor Intensive Operating Period," Proc. Eighth ARM Science Team Meeting, March 23-27th, 1998, Tucson, Arizona, (in press).

E. N. Kadygrov, Gaikovich, K. P., Westwater, E. R., Han, Y., and Widener, K. (1998): Potential performance of boundary layer temperature profile microwave remote sensing: Results of field testing at various latitude zones. Proc. Eighth ARM Science Team Meeting, March 23-27th, 1998, Tucson, Arizona, 353-357.

J. C. Liljegren, E. R. Westwater, and Y. Han: (1998): "A comparison of integrated water vapor sensors: WVIOP-96," Proc. Seventh ARM Science Team Meeting, March 3-7, 1997, San Antonio, Texas, pp. 1-4.

P. E. Racette, E. R. Westwater, Y. Han, Al Gasiewski,Ed Kim, M. Klein, K. Widener, B. Zak (1999):Millimeter Wave Radiometric Arctic Winter Experiment. Proc. $9^{\text {th }}$ ARM Science Team Meeting, San Antonio, Texas, March 22-26, 1999 (in press).

E. R. Westwater, Y. Han, S. I. Gutman, and D. E. Wolfe: (1998) "Remote sensing of column integrated water vapor by microwave radiometers and GPS during the 1997 Water Vapor Intensive Operating Period," Proc. Eighth ARM Science Team Meeting, March 23-27th, 1998, Tucson, Arizona, 799-803.

E. R. Westwater, Y. Han, V. G. Irisov, V. Leuskiy, E. N. Kadygrov, and S. A. Viazankin (1997): "Remote Sensing of Boundary-Layer Temperature Profiles by a Scanning 5-mm Microwave Radiometer and RASS: A Comparison Experiment." Proc. IGARSS'97, 4-8 August 1997, Singapore.2093-2096. 
E. R. Westwater, Y. Han, V. Leuskiy, V. Irisov, E. Kadygrov, and S. A. Vaizankin (1998): Multi-Sensor Measurements of Boundary-Layer Temperature Profiles. Proceedings of Seventh ARM Science Team Meeting, March 3-7, 1997, pp. 311-315.

E. R. Westwater, Y. Han, V. G. Irisov, V. Ye Leuskiy, Yu. G. Trokhimovskiy, and C. W. Fairall (1998): Evaluation of a Scanning 5-mm Radiometer for Obtaining Air-Sea Temperature

Difference and Low-Level Atmospheric Stability. Proceedings of Seventh ARM Science Team Meeting, March 3-7, 1997, pp. 245-249.

E. R. Westwater, Y. Han, S. I. Gutman, and D. E. Wolfe: (1998): "Remote sensing of total precipitable water vapor by microwave radiometers and GPS during the 1997 Water Vapor Intensive Operating Period," Proc. IGARSS'9, 6-19 July, 1998, Seattle, WA, pp. 2158-2162.

E. R. Westwater, Y. Han, K. Gaikovich, E. N. Kadygrov, and A. S. Viazankin, (1998): "Remote sensing of boundary layer temperature profiles by scanning microwave radiometers and RASS: results of an intercomparison experiment," Proc. $4^{\text {th }}$ Int. Sym. on Tropospheric Profiling, Snowmass, Colorado, (323-325).

Ed R. Westwater, Yong Han, and Fred Solheim (1999): A Multifrequency Scanning Microwave Radiometer for Temperature Profiling Proc. $9^{\text {th }}$ ARM Science Team Meeting, San Antonio, Texas, March 22-26, 1999 (in press). 